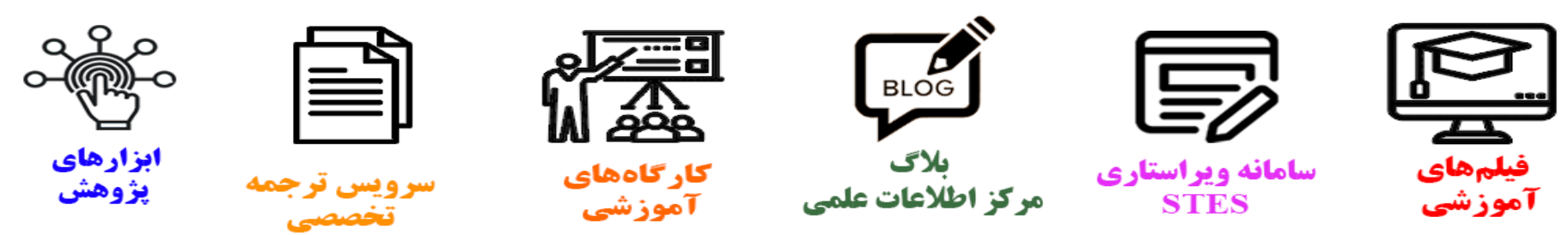

\title{
(c)
}

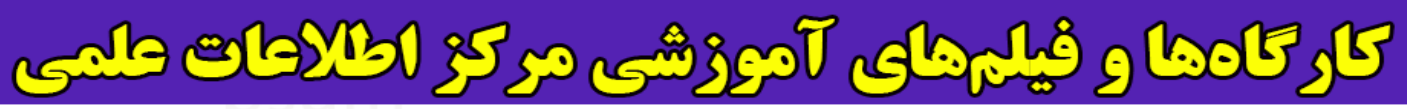
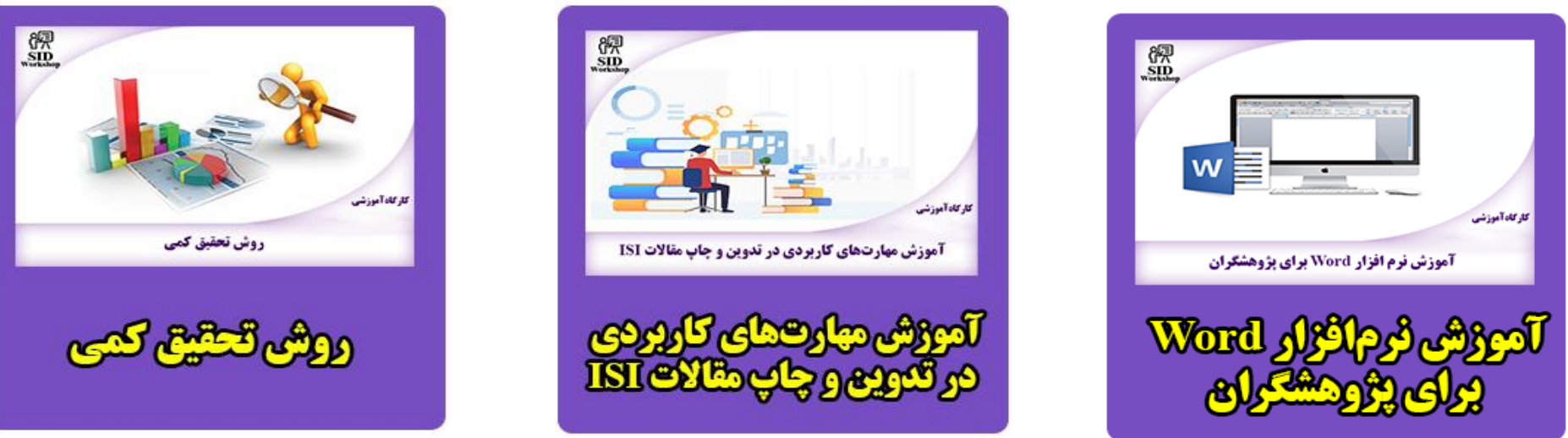


\title{
International Journal of Engineering
}

Journal Hom e page: ww w. ije.ir

\section{A Procedure for Preparation of Semi-activated Carbon Fiber without any Treatment under High Temperature}

\author{
N. Saeidi, M. N. Lotfollahi* \\ School of Chemical, Gas and Petroleum Engineering, Semnan University, Semnan, Iran
}

\section{PAPER INFO}

Paper history:

Received 05 March 2014

Received in revised form 18 May 2014

Accepted 22 May 2014

\section{Keywords:}

Activated Carbon Fiber

Organic Binder

Iodine Number

Adsorption Property

Mechanical Property

\section{$\begin{array}{lllllllll}A & B & S & T & R & A & C & T\end{array}$}

A procedure for preparing the semi-activated carbon fiber (SACF) at low temperature is proposed. The first step of the procedure is coating of an inorganic fiber (E-glass fiber) by an adsorbent mixture (powder activated carbon) using methyl cellulose and water as gluing material. In this work, a set of experiments were performed to attain appropriate adsorbent mixture for good quality coating. The best composition was investigated based on the adsorption and the mechanical properties of the coated fibers. The results showed that an adsorbent mixture containing 3 to $4 \mathrm{wt} \%$ of methyl cellulose, and $15-20 \mathrm{wt} \%$ of activated carbon renders good quality coating. The adsorption property of the coated fibers was studied by determination of iodine number for the adsorbent mixture. In this work, the weight percent of the coated adsorbent mixture on the fibers have also been measured and reported. The mechanical properties were examined by flow of air through a packing of the coated fibers. BET surface area of the samples was also examined and compared to other reported works. The results showed that the surfaces area of the samples were either equal to or higher than other disclosed works. In order to test the weight loss of the coated fibers, the weight of packing was measured after 20, 40 and 60 min flowing of air through the packing. The weight loss in all cases was very low (up to 0.001 g); thus good quality of coating was occurred.

\section{INTRODUCTION}

Activated carbons as the nanoporous materials with high surface area are of interest as adsorbent in many industries such as food processing, pharmaceuticals, chemical, petroleum, mining and nuclear industries. They are used in the automobile, air conditioner or air purifier, water treatment and vacuum manufacturing [15]. This diversity of applications depends on the surface properties and the shape of activated carbon. Activated carbons are classified into different types according to their size and shape: powder, granular, activated carbon fiber and shaped form (such as honeycomb structure). Each type of activated carbon has its specific applications in different industries [6-12]. Although activated carbon is used in many purification applications in the form of granule or pellet, but the

*Corresponding Author's Email: mnlotfollahi@semnan.ac.ir (M. N. Lotfollahi ) major problem with these forms of carbon is highpressure drop that occurs in their packed bed. The other problems in relation with the use of granular activated carbon are entrainment of the powder in the flow stream and abrasion of the granules. One solution way for the mentioned problems is using the activated carbon fiber (ACF) or honeycomb structure activated carbon [1316]. ACFs have very wide applications in industries, particularly, for removal of pollutants from water or air. The applications of ACF have been widely extended, not only as an adsorbent but also as a catalyst support and as an electronic material [15, 17-19]. Different preparation methods for the ACF were proposed in the literature [15, 20-22]. Eomet al. [15] prepared the ACF through differently shaped spinnerets from pitch precursor. They activated the carbon fiber in steam media. Characterization of these differently shaped ACFs was carried out in relation to the activation energy, rate and adsorption capacity. In this work, there are two heat treatment steps, namely, stabilization and 
carbonization. To attain ACFs with good adsorption capacity, they performed the treatments under high temperature. Stabilization and carbonization were performed at 280 and $1000^{\circ} \mathrm{C}$, respectively. They could not attain the products with high adsorption capacity. In addition, they did not examine the mechanical properties of their product. It can be mentioned that the heat treatment under high temperature adversely affected the mechanical strength of the product. Vilaplana-Ortego et al. [20] prepared activated carbon fiber monoliths by physical activation of the fiber monolith rived from two kinds of pitch-based carbon fiber $(\mathrm{CF})$. In this work, the authors were forced to perform activation under high temperature.

In another reported work, Im et al. [22] prepared ACF by electro-spinning method. Electro-spinning is accomplished by inducing a large electric potential (typically 15-30 $\mathrm{kV}$ direct current) in a polymer solution (or melt) that is separated by some distance from an oppositely charged target to create a static electric field. As the electric field potential increases, the electrostatic forces in the solution overcome the surface tension of the solution and a thin liquid jet composed of entangled polymer chains is ejected from the polymer reservoir. The jet then travels through space (this condition was previously described as whipping motion of the fiber). As the liquid jet travels through space, the solvent evaporates forming a fiber that deposits as a dry, fibrous structure, and eventually, a nonwoven material can be collected on the target. To activate the ACF, they used physical activation. In the activation method, they attached silica nanoparticles to the ACF before electro-spinning. After stabilization, the silica nanoparticle was extracted by HF acid. They did not treat the fibers under high temperature. However, their ACF did not have proper surface area. In their work, polyacrylonitrile was used as carbon source.

Kim et al. [23] also used the electro-spinning method to prepare activated carbon fiber. They used polyamic acid as carbon source. In the previously mentioned work, stabilization step was done under high temperature, 700 to $1000^{\circ} \mathrm{C}$. The stabilized fibers were activated by steam at 650 to $850^{\circ} \mathrm{C}$. However, the synthesized fibers did not have the proper surface area, and mechanical strength of the fibers were not examined. Therefore, in the two recent mentioned works, the authors used electro-spinning method, but with two different techniques for activation of the fibers.

Park and Kim [24] disclosed a procedure to prepare activated carbon fiber by molding. They used polyacrylonitrile as carbon source. Phenolic resin was used to reinforce the fibers. The procedure consisted of two heat treatment steps at high temperature (around $1000^{\circ} \mathrm{C}$ ). On the other hand, the phenolic resin used to reinforce the fibers led to decrease surface area of the ACFs. Oya et al.[25] prepared ACF by spinning method. They used phenolic resin as carbon source. In the process, there are two heat treatment processes, carbonization at and activation, both at $900^{\circ} \mathrm{C}$. The activation step was performed by steam. The fibers had proper mechanical strength, but not a good surface area. Mohammad et al. [26] prepared ACF using commercial polyacrylonitrile (PAN) fiber. They performed two vigorous heat treatment steps to stabilize, carbonize and activate the fiber. Giraldo et al.[27] used Kevlar [poly (p-phenilylene terephtalamide)] fiber to prepare ACF. They used three heat treatment steps, including both steam and $\mathrm{CO}_{2}$ activation at around $1000^{\circ} \mathrm{C}$.

Economy et al.[28] have developed a relatively low cost procedure in which phenolic resin as precursor was coated on glass fibers. The key factor in this approach is the use of low cost glass fiber. However, their work had a few vulnerable spots, while the use of low cost glass fiber was a good idea to prepare SACF. Following this work, a few researchers studied on preparation of SACF and tried to increase the quality of the fibers, including adsorption capacity and mechanical strength, and decrease the cost of the products. Jeong et al.[29] evaluated the possibility of using coal tar pitch instead of phenolic resin for coating on glass fiber because of its lower cost compared to phenolic resin. In addition, in other reported work [30] a procedure was described for coating glass fiber by a mixture of coal tar pitch and phenolic resin. In such works, the glass fibers after coating by precursors (pitch and phenolic resin) were treated under high temperature $\left(500-1000^{\circ} \mathrm{C}\right)$. The treatment includes carbonization and activation. These treatments may adversely affect the shape and mechanical strength of the products. Also, as mentioned earlier, SACF can be used as a catalyst support. Therefore, treating under high temperature may damage the loaded material on the catalyst support.

In all the above-mentioned works, there were at least two heat treatment steps under high temperature to stabilize, carbonize and activate the ACF and SACF. As mentioned earlier, the treatments adversely affect on the physical shape and mechanical strength of the products. Also, such procedures are relatively expensive and timeconsuming.

By using powder activated carbon instead of phenolic resin in coating the glass fiber, there is no need for thermal treatments on the coated glass fiber at high temperature. To the best of our knowledge, the possibility of coating glass fiber by powder activated carbon has not been yet examined.

In this work, a procedure is described for coating powder activated carbon on glass fibers in gas phase. In fact, the aim of this work was to prepare SACF by coating glass fibers with an adsorbent mixture including powder activated carbon, methyl cellulose as organic polymer binder and water. In contrast to the other reported works for preparation of SACF, in this procedure there is not any treatment step under high temperature. Instead, a few solutions were applied to 
prevent blocking the pores of powder activated carbon by the binder. In order to reach a good coating, a variety of products was produced with different compositions of activated carbon, methyl cellulose and water in the adsorbent mixture. Then, adsorption, surface area and mechanical properties of the coated fibers were measured and compared with data reported in literature.

\section{EXPERIMENTAL}

2. 1. Material Methyl cellulose was obtained from BDH Company (England) as a binder. The methyl cellulose has a gelation temperature of around $45^{\circ} \mathrm{C}$, below which it is completely soluble in water. Powder activated carbon was obtained from Jacobi Company (Sweden). Choloridric acid, iodine, potassium iodide, starch and sodium thiosulfate were obtained from Merck Company (Germany), all with mass fraction purity greater than 0.99 . All the chemicals were used without any further purification. The E-glass fiber with about $0.5 \mathrm{~mm}$ thickness was provided from Qingdao strong M\&E Co. Ltd (China).

\section{1. 1. Characteristics of the Powder Activated} Carbon Particle size distribution of the purchased activated carbon was determined by standard sieves equipped with a shaker (E.L.M, SIE. 35). Table 1 shows the activated carbon particle size distribution. Using the this particle size distribution, the mean particle size of powder activated carbon was calculated to be $109 \mu \mathrm{m}$. The measured Iodine number of the powder activated carbon based on the ASTM D4607-94 [31] is about $1360 \mathrm{mg} / \mathrm{g}$. In this work, all the iodine number measurements were performed three times and the average value has been reported.

Figure 1 shows the pore size distribution of the powder activated carbon. The Analysis was performed using BJH method [32] and by utilizing nitrogen desorption isotherm data. As can be seen in Figure 1, most of pores have a radius of around $10 \mathrm{~nm}$.

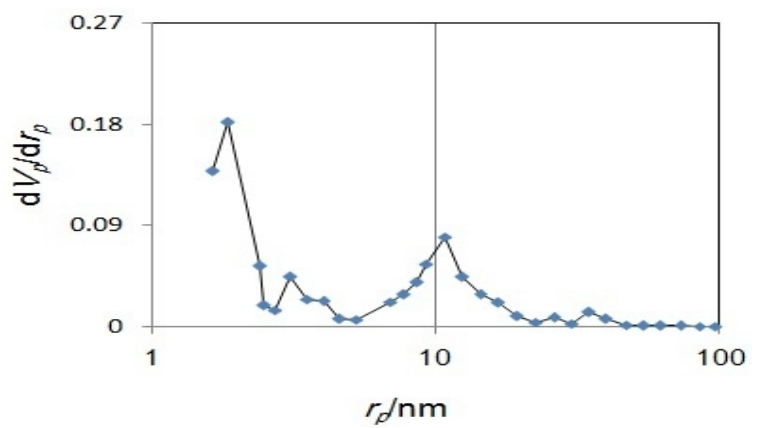

Figure 1. Pore size distribution of the powder activated carbon.
TABLE 1. Particle size distribution of the activated carbon

\begin{tabular}{ccc}
\hline Mesh number & $\mathbf{m} \boldsymbol{\mu}$ & Weight fraction \\
\hline 40 & 420 & 0.0079 \\
80 & 177 & 0.2452 \\
120 & 125 & 0.3818 \\
270 & 53 & 0.0542 \\
325 & 44 & 0.0613 \\
400 & 37 & 0.2496 \\
\hline
\end{tabular}

2. 2. Coating of the Fibers In this work, the coating was performed by dip-coating method [33] with several alterations. For this, a mixture including powder activated carbon, methyl cellulose and water was mixed using a laboratory mixer at about $300 \mathrm{rpm}$ and $50^{\circ} \mathrm{C}$ for $15 \mathrm{~min}$. In this condition the prepared mixture had suitable viscosity (around $150 \mathrm{cP}$ ) for dip-coating. Then, the fibers $\left(1.92 \mathrm{~g}\right.$ and $\left.12 \mathrm{~cm}^{2}\right)$ were simply dipped in this mixture, allowed to soak for a few minutes and drained of the excess mixture by subjecting the fibers under a force 15 Newton for one minute. Finally, the prepared fibers were dried in an oven at $60^{\circ} \mathrm{C}$ for 3 hours. In the above mentioned step for preparation of the coated mixture, the temperature was regulated by a thermostatic bath (Grant instruments (Cambridge) Ltd. (type SE 15, England)), accurate to $\pm 0.2{ }^{\circ} \mathrm{C}$. The components were weighed on an analytical balance (A\&D Company, GF-600, Japan) accurate to $0.001 \mathrm{~g}$. It is important to note that mixing a binder with powder activated carbon at high speeds prevents the block age of the pores of activated carbon and improves adsorption capacity of the prepared mixture [34].

\section{RESULTS AND DISCUSSION}

3. 1. Quality of Coating In the present work, a set of experiments was performed to attain appropriate adsorbent mixture for good quality of coating. We first coated the fibers by various composition of the adsorbent mixture, and then the quality of coating was examined by SEM images. The images were recorded using XL30 Philips. The experiments started with the minimum composition of methyl cellulose $(1 \mathrm{wt} \%)$ as the organic binder. The produced fibers did not have good coverage with the adsorbent mixture in this composition of methyl cellulose. In other words, the coater adsorbent mixture could not fill the voids between the fibers, and the coating quality was poor. The experiments were continued for the adsorbent mixture containing $2 \mathrm{wt} \%$ methyl cellulose and various percentages of activated carbon. Poor coating quality was also observed in this case. It can be concluded that the minimum useable composition of methyl cellulose is $3 \mathrm{wt} \%$. Table 2 shows the compositions of adsorbent 
mixture with more than $3 w t \%$ of methyl cellulose. In this table the wt $\%$ of the coated mixture on the fibers is also reported. Figure 2 shows SEM images of the coated fibers by mixture containing $3 \mathrm{wt} \%$ of methyl cellulose and various percentages of activated carbon (15, 20 and $25 \mathrm{wt} \%$ in Figure 2, a, b and c, respectively). As it can be seen in Figure 2 (a), the coater adsorbent mixture did not well fill the voids between the fibers. Figure 2 (c) shows that the SEM image of the produced activated carbon fiber demonstrated better coating with respect to the prior cases (in Figure 2 (a) and 1 (b)). The experiments with higher percentages of activated carbon $(30 \mathrm{wt} \%)$ in the coater adsorbent mixture showed that the coater adsorbent mixture was viscous And it was impossible to use dip-coating method. For the adsorbent mixture containing $4 \mathrm{wt} \%$ methyl cellulose and various percentages of activated carbon, the same results were obtained. By increasing the wt $\%$ of methyl cellulose from 4 to $5 \mathrm{wt} \%$, the coater adsorbent mixture was semiplastic and coating was impossible.

3. 2. Adsorption Capability To compare the adsorption properties of the coated fibers, we defined the parameter "adsorption capability" to show the effects of both adsorption and coating abilities of produced fibers. The adsorption capability parameter depends on both iodine number of the adsorbent mixture and weight of the coated adsorbent mixture on the fibers. The adsorption capability is defined as follows:

$\frac{(a \times b)}{c}=d$

where, a denotes iodine number of the adsorbent mixture $(\mathrm{mg} / \mathrm{g}), \quad b$ weight of the coated adsorbent mixture $(\mathrm{g}), \quad c$ surface of the fiber $\left(\mathrm{cm}^{2}\right)$ and $d$ adsorption capability $\left(\mathrm{mg} / \mathrm{cm}^{2}\right)$. (a)

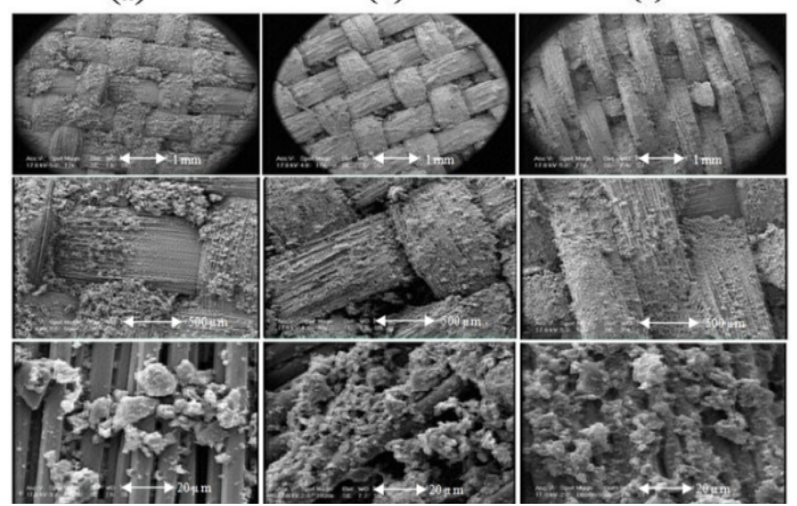

Figure 2. SEM images of the coated fibers, (a) $3 \mathrm{wt} \%$ methyl cellulose and $15 \mathrm{wt} \%$ activated carbon, (b) $3 \mathrm{wt} \%$ methyl cellulose and $20 \mathrm{wt} \%$ activated carbon, (c) $3 \mathrm{wt} \%$ methyl cellulose and $25 \mathrm{wt} \%$ activated carbon.

TABLE 2. Wt $\%$ of the coated adsorbent mixture on the fibers.

\begin{tabular}{cccc}
\hline $\begin{array}{c}\text { Run } \\
\text { No. }\end{array}$ & $\begin{array}{c}\text { Wt\% of } \\
\text { methyl } \\
\text { cellulose }\end{array}$ & $\begin{array}{c}\text { Wt\% of } \\
\text { activated } \\
\text { carbon }\end{array}$ & $\begin{array}{c}\text { Wt\% of the coated } \\
\text { mixture on the } \\
\text { fibers a }\end{array}$ \\
\hline
\end{tabular}

\begin{tabular}{llcc}
\hline $\mathbf{1}$ & 3 & 5 & 15 \\
$\mathbf{2}$ & 3 & 10 & 22 \\
$\mathbf{3}$ & 3 & 15 & 34.8 \\
$\mathbf{4}$ & 3 & 20 & 42.8 \\
$\mathbf{5}$ & 3 & 25 & 48.7 \\
$\mathbf{7}$ & 4 & 5 & 17 \\
$\mathbf{8}$ & 4 & 10 & 26 \\
$\mathbf{9}$ & 4 & 15 & 38.4 \\
$\mathbf{1 0}$ & 4 & 20 & 45.1 \\
$\mathbf{1 1}$ & 4 & 25 & 49.9 \\
\hline-
\end{tabular}

a $-\mathrm{Wt} \%$ of the coated mixture on the fibers $=[$ (Weight of the coated fiber $(\mathrm{g})$ Weight of the fiber before coating $(\mathrm{g})) /$ Weight of the coated fiber $(\mathrm{g})] * 100$

TABLE 3. Adsorption capability of the coated fibers

\begin{tabular}{cccccc}
\hline Sample & $\begin{array}{c}\text { Wt\% methyl } \\
\text { cellulose }\end{array}$ & $\begin{array}{c}\text { Wt\% activated } \\
\text { carbon }\end{array}$ & $\begin{array}{c}\text { Iodine number of the adsorbent } \\
\text { mixture (mg/g) }\end{array}$ & $\begin{array}{c}\text { Weight of the coated } \\
\text { adsorbent mixture }{ }^{\mathbf{( g}} \mathbf{( g )}\end{array}$ & $\begin{array}{c}\text { Adsorption capability } \\
\left(\mathbf{m g} / \mathbf{c m}^{2}\right)\end{array}$ \\
\hline S1 & 3 & 15 & 1295.234 & 1.029 & 111.066 \\
S2 & 3 & 20 & 1308.762 & 1.439 & 156.942 \\
S3 & 3 & 25 & 1324.551 & 1.829 & 201.883 \\
S4 & 4 & 15 & 1283.342 & 1.199 & 128.227 \\
S5 & 4 & 20 & 1297.711 & 1.578 & 170.649 \\
S6 & 4 & 25 & 1314.892 & 1.916 & 209.944 \\
\hline
\end{tabular}

\footnotetext{
${ }^{\mathrm{a}}$ - Weight of the coated adsorbent mixture $=$ Weight of the coated fiber $(\mathrm{g})$ - Weight of the fiber before coating $(\mathrm{g})$
} 
TABLE 4. Surface area of the synthesized samples in this work and other works.

\begin{tabular}{|c|c|c|}
\hline Sample & BET surface area $\left(\mathrm{m}^{2} / \mathrm{g}\right)$ & Synthesis method \\
\hline S1 & 715 & Present work \\
\hline S2 & 793 & Present work \\
\hline S3 & 867 & Present work \\
\hline S4 & 652 & Present work \\
\hline S5 & 722 & Present work \\
\hline S6 & 796 & Present work \\
\hline [22] & 450 & Electrospinning \\
\hline [22] & 550 & Electrospinning \\
\hline [23] & 622 & Electrospinning \\
\hline [24] & 340 & Molding process \\
\hline [24] & 482 & Molding process \\
\hline [24] & 576 & Molding process \\
\hline [25] & 280 & Spinning \\
\hline [26] & 675 & Activation of PAN fiber \\
\hline [26] & 536 & Activation of PAN fiber \\
\hline [27] & 458 & Activation of kevlar fiber \\
\hline [27] & 251 & Activation of kevlar fiber \\
\hline [27] & 403 & Activation of kevlar fiber \\
\hline [30] & 430 & Coating inorganic fibers \\
\hline [30] & 730 & Coating inorganic fibers \\
\hline
\end{tabular}

In fact, the adsorption capability indicates the adsorbed iodine per unit area of the coated fibers. The iodine number of the adsorbent mixture was determined based on the ASTM D4607-94 standard. Table 3 shows the iodine number of adsorbent mixture, the weight of coated adsorbent and the adsorption capability for various $\mathrm{wt} \%$ of methyl cellulose and $\mathrm{wt} \%$ of activated carbon. The results showed that with increasing of activated carbon $\mathrm{wt} \%$, both the $\mathrm{wt} \%$ of coated adsorbent and the iodine number increased and consequently the adsorption capability of the coated fibers also increased. As can be seen in Figure 3, increasing the wt $\%$ of the methyl cellulose in spite of reducing the iodine number, caused an increase in the adsorption capability. Noting the above mentioned results, it can be concluded that for improving the adsorption capability of the SACFs, increasing the amount of coated adsorbent mixture on the fibers is more effective than to improve adsorption capacity (iodine number) of the adsorbent mixture.

3. 3. Surface Area The nitrogen adsorption and desorption isotherms for the coated fibers were measured at $-196^{\circ} \mathrm{C}$ on a Belsorp 18 (BEL Japan, Ltd.). The samples were heated at $200^{\circ} \mathrm{C}$ for 2 hours and degassed overnight. The specific surface area was determined by the Brunaver-Emmet-Teller (BET) method [35] using $a_{m}\left(N_{2}=16.2 \AA^{2}\right)$, where, $a_{m}$, is the molecular area of nitrogen at $-196^{\circ} \mathrm{C}$. Table 4 shows the results and a comparison between the synthesized samples in the present work and otherdisclosed works.

As can be seen in Table 4, the surfaces areaof all synthesized samples in the present work are either almost equal to or higher than the surfaces area of two other reported works. Thus, it can be concluded that the synthesized samples in the present work have very good surface area. Therefore, it can be concluded that the binder has very low adverse effect on the powder activated carbon. In fact, minimizing the amount of the binder in the coater mixture led to prevention of blocking pores of powder activated carbon by binder, and subsequently, decreasing surface area of the coated fibers.

3. 4. Mechanical Property There is a weight loss by abrasion in the continuous adsorption processes for the shaped and granular activated carbon. It is reported in the literature that the abrasion increases the pressure drop in continuous processes [36]. Therefore, the mechanical properties of the products could be tested by flowing air through a packing of the products and measure the weight loss. In order to carry out this experiment, a set-up was assembled (Figure 4). In this work, the weight loss of the coated fiber packing was measured after 20, 40 and 60 min flowing of air (165 $1 / \mathrm{min})$. Table 5 shows the results.

As can be seen in Table 5, the weight loss in all cases was very low. The weight loss of the coated fibers increased by increasing the activated carbon content of adsorbent mixture, but it decreased by increasing the methyl cellulose content from 3 to $4 \%$ wt. The values of weight losses obtained after 40 and 60 minutes flow of air were almost equal in all cases.

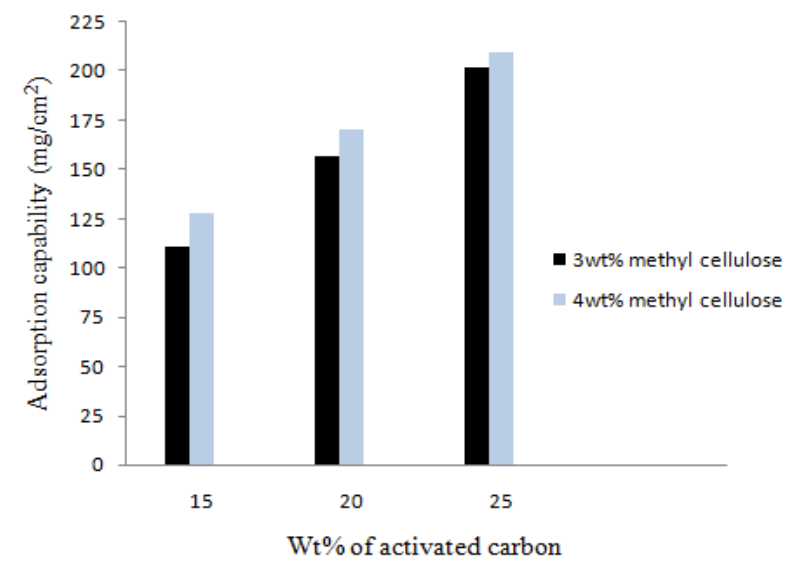

Figure 3. Comparison of the adsorption capability of the coated fibers 
TABLE 5. Weight loss of the coated fibers after 20, 40 and 60 minutes flowing of air (165 lit / min).

\begin{tabular}{|c|c|c|c|c|c|}
\hline Sample & $\begin{array}{c}\text { Wt\% methyl } \\
\text { cellulose }\end{array}$ & $\begin{array}{c}\text { Wt } \% \text { activated } \\
\text { carbon }\end{array}$ & $\begin{array}{c}\text { Weight loss after } 20 \\
\text { minutes flowing of air }^{\text {a }}(\mathrm{g}) \\
\end{array}$ & $\begin{array}{c}\text { Weight loss after } 40 \\
\text { minutes flowing of air }{ }^{\text {a }}(\mathrm{g}) \\
\end{array}$ & $\begin{array}{c}\text { Weight loss after } 60 \text { minutes } \\
\text { flowing of air }{ }^{\text {a }}(\mathrm{g})\end{array}$ \\
\hline S1 & 3 & 15 & 0.007 & 0.009 & 0.009 \\
\hline S2 & 3 & 20 & 0.01 & 0.014 & 0.015 \\
\hline S3 & 3 & 25 & 0.012 & 0.016 & 0.016 \\
\hline S4 & 4 & 15 & 0.005 & 0.005 & 0.005 \\
\hline S5 & 4 & 20 & 0.008 & 0.01 & 0.01 \\
\hline S6 & 4 & 25 & 0.01 & 0.015 & 0.017 \\
\hline
\end{tabular}

${ }^{a}$-Weight loss of the coated fiber $(\mathrm{g})=$ Weight of the coated fiber before flowing of air $(\mathrm{g})$ - Weight of the coated fiber after flowing of air $(\mathrm{g})$

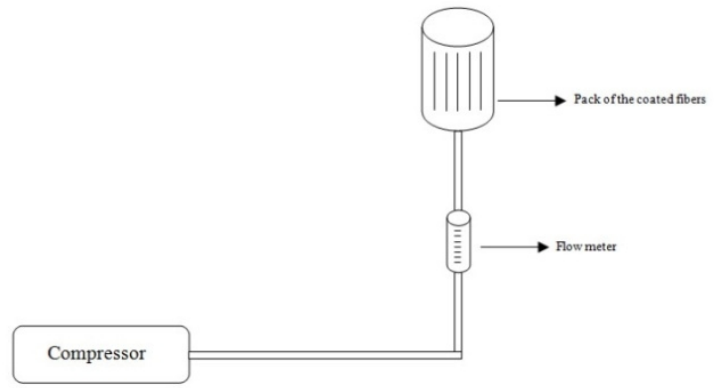

Figure 4. Experimental set up for flowing air through the packing.

\section{CONCLUDING REMARKS}

In this work a set of experiments was performed to attain appropriate adsorbent mixture for good quality of coating. The best composition was investigated based on the adsorption and the mechanical properties of the coated fibers. The parameter "adsorption capability" was defined to show the effects of both adsorption properties and coating abilities of produced fibers. The adsorption capability depends on both the iodine number of the coater mixture and the weight of the coated mixture on the fibers. It was found that an adsorbent mixture containing $3 \mathrm{wt} \%$ or $4 \mathrm{wt} \%$ of methyl cellulose, and $15-20 \mathrm{wt} \%$ of activated carbon represents good quality of coating. By increasing the wt $\%$ of methyl cellulose from 3 to $4 \mathrm{wt} \%$ the iodine number of the adsorbent mixtures decreased, but weight of the coated adsorbent mixture on the fibers was increased. The results showed that the adsorption capability of the fibers that were coated with the adsorption mixture containing $4 \mathrm{wt} \%$ of methyl cellulose was higher than the adsorption capability of the fibers that were coated with the adsorption mixture containing $3 \mathrm{wt} \%$ of methyl cellulose.

Surface area of the coated fibers was attained by BET method. The results showed that the coated fibers in the present work have more acceptable surface areas than that of other reported works. Also, as can be seen in Table 3 and by noting the iodine number of the initial powder activated carbon, the adsorption capacity of the coated fibers is about $95 \%$ compared with that of the initial powder. In other word, only less than $5 \%$ of adsorption capacity of the initial powder activated carbon decreased. It means that the procedure did not lead to block the pores of the initial powder.

The weight loss of the coated fibers in packing was measured after 20,40 and 60 min flowing of air. The weight loss in all cases was very low, thus good quality of coating can be inferred. The values of weight losses obtained after 40 and 60 minutes flowing of air were almost equal in all cases. Finally, it must be noted that in the present work, a procedure for preparing semi activated carbon fiber with good adsorption and strength quality and without any treatment under high temperature is proposed.

\section{REFERENCES}

1. Bansal, R.C., Donnet, J.-B. and Stoeckli, F., "Active carbon, M. Dekker, (1988).

2. R.F., R. and and Sepulveda E.A., "Handbook of surfaces and interfaces of materials, biomolecules, biointerfaces and applications, San diego, academic press, Vol. 5, (2001).

3. Ninković, M.B., Petrović, R.D. and Laušević, M.D., "Removal of organochlorine pesticides from water using virgin and regenerated granular activated carbon", Journal of the Serbian Chemical Society, Vol. 75, No. 4, (2010), 565-573.

4. Anbia, M. and Ghaffari, A., "Modified nanoporous carbon material for anionic dye removal from aqueous solution", International Journal of Engineering-Transactions B: Applications, Vol. 25, No. 4, (2012), 259-268.

5. Radnia, H., Ghoreyshi, A., Younesi, H., Masomi, M. and Pirzadeh, K., "Adsorption of fe (ii) from aqueous phase by chitosan: Application of physical models and artificial neural network for prediction of breakthrough", International Journal of Engineering-Transactions B: Applications, Vol. 26, No. 8, (2013), 845-854.

6. Zhang, X., Zhang, Y., Wang, S., Zhang, J. and Zhou, W., "Effect of activation agents on the surface chemical properties and desulphurization performance of activated carbon", Science China Technological Sciences, Vol. 53, No. 9, (2010), 25152520 .

7. El-Hendawy, A.-N.A., Samra, S. and Girgis, B., "Adsorption characteristics of activated carbons obtained from corncobs", 
Colloids and Surfaces A: Physicochemical and Engineering Aspects, Vol. 180, No. 3, (2001), 209-221.

8. Kim, J.W., Sohn, M.H., Kim, D.S., Sohn, S.M. and and Kwon, Y.S., "Production of granular activated carbon from waste walnut shell and its adsorption characteristics for cu2+ ion", Journal of Hazardous Material, Vol. 85, No., (2001), 301-312.

9. Chai, X., Jia, J., Sun, T., Wang, Y. and Liao, L., "Application of a novel cold activated carbon fiber-solid phase microextraction for analysis of organochlorine pesticides in soil", Journal of Environmental Science and Health Part B, Vol. 42, No. 6, (2007), 629-634.

10. Carvalho, A., Mestre, A., Pires, J., Pinto, M. and Rosa, M.E., "Granular activated carbons from powdered samples using clays as binders for the adsorption of organic vapours", Microporous and Mesoporous Materials, Vol. 93, No. 1, (2006), 226-231.

11. Pinto, M.L., Pires, J., Carvalho, A.P., de Carvalho, M.B. and Bordado, J.C., "Characterization of adsorbent materials supported on polyurethane foams by nitrogen and toluene adsorption", Microporous and Mesoporous Materials, Vol. 80, No. 1, (2005), 253-262.

12. Son, G. and Lee, S., "Application of micellar enhanced ultrafiltration and activated carbon fiber hybrid processes for lead removal from an aqueous solution", Korean Journal of Chemical Engineering, Vol. 28, No. 3, (2011), 793-799.

13. Gadkaree, k.P.M. and joseph, F. Washington, D.C.: U. S. Patent and Trademark Office.(1996)

14. . Dana C., D., Ronald, E.J. and Streicher, P. Washington, D.C.: U.S. Patent and Trademark Office.(1995)

15. Eom, S.-Y. and Ryu, S.-K., "Properties of differently shaped activated carbon fibers", Korean Journal of Chemical Engineering, Vol. 27, No. 5, (2010), 1592-1595.

16. Lim, J.-W., Choi, Y., Yoon, H.-S., Park, Y.-K., Yim, J.-H. and Jeon, J.-K., "Extrusion of honeycomb monoliths employed with activated carbon-ldpe hybrid materials", Journal of Industrial and Engineering Chemistry, Vol. 16, No. 1, (2010), 51-56.

17. Donnet, J.-B., "Carbon fibers, CRC Press, (1998).

18. Kang, T.J., Shin, S.J., Jung, K. and Park, J.K., "Mechanical, thermal and ablative properties of interply continuous/spun hybrid carbon composites", Carbon, Vol. 44, No. 5, (2006), 833-839.

19. Li, L., Quinlivan, P.A. and Knappe, D.R., "Effects of activated carbon surface chemistry and pore structure on the adsorption of organic contaminants from aqueous solution", Carbon, Vol. 40, No. 12, (2002), 2085-2100.

20. Vilaplana-Ortego, E., Alcañiz-Monge, J., Cazorla-Amorós, D. and Linares-Solano, A., "Activated carbon fibre monoliths", Fuel Processing Technology, Vol. 77, No., (2002), 445-451.

21. Economy, J., Li, E.Y. and Murty.Washington, D.C.: U.S. Patent and Trademark Office.(1975)
22. Im, J.S., Jang, J.-S. and Lee, Y.-S., "Synthesis and characterization of mesoporous electrospun carbon fibers derived from silica template", Journal of Industrial and Engineering Chemistry, Vol. 15, No. 6, (2009), 914-918.

23. Kim, C., Choi, Y.-O., Lee, W.-J. and Yang, K.-S., "Supercapacitor performances of activated carbon fiber webs prepared by electrospinning of pmda-oda poly (amic acid) solutions", Electrochimica Acta, Vol. 50, No. 2, (2004), 883887.

24. Park, S.-J. and Kim, K.-D., "Influence of activation temperature on adsorption characteristics of activated carbon fiber composites", Carbon, Vol. 39, No. 11, (2001), 1741-1746.

25. Oya, A., Yoshida, S., Abe, Y., Iizuka, T. and Makiyama, N., "Antibacterial activated carbon fiber derived from phenolic resin containing silver nitrate", Carbon, Vol. 31, No. 1, (1993), 7173.

26. Zaini, M.A.A., Amano, Y. and Machida, M., "Adsorption of heavy metals onto activated carbons derived from polyacrylonitrile fiber", Journal of Hazardous Materials, Vol. 180, No. 1, (2010), 552-560.

27. Giraldo, L., Ladino, Y., Pirajánc, J. and Rodríguez, M., "Synthesis and characterization of activated carbon fibers from kevlar", Eclética Química, Vol. 32, No. 4, (2007), 55-62.

28. Economy, J., Michael, M.A. and Mangun, C.L., " in Proceedings of the 89th annual Meeting of Air and Waste Management Association, Nashville, Tennessee U. S. (1996).

29. Jeong, A.Y., Cho, D.H., Lee, S.H. and Kiln, D.P., Journal of the Korean Ceramic Society, Vol. 36, No., (1999), 756-770

30. Baek, I., "Preparation of semi-activated carbon fibers", Korean Journal of Chemical Engineering, Vol. 17, No. 5, (2000), 553558 .

31. ASTM D 4607-94 Philadelphia, P.A.C.o.S. (2006).

32. Barrett, E.P., Joyner, L.G. and Halenda, P.P., "The determination of pore volume and area distributions in porous substances. I. Computations from nitrogen isotherms", Journal of the American Chemical society, Vol. 73, No. 1, (1951), 373380 .

33. Moreno-Castilla, C. and Pérez-Cadenas, A.F., "Carbon-based honeycomb monoliths for environmental gas-phase applications", Materials, Vol. 3, No. 2, (2010), 1203-1227.

34. . Yan, Z.Q., McCue, J.C. and Tolles, E.D. Washington, D.C.: U.S. Patent and Trademark Office.(1996)

35. Brunauer, S., Emmett, P.H. and Teller, E., "Adsorption of gases in multimolecular layers", Journal of the American Chemical society, Vol. 60, No. 2, (1938), 309-319.

36. Miller, J.R.: Washington, D.C.: U.S. Patent and Trademark Office, (1998) 


\section{A Procedure for Preparation of Semi-activated Carbon Fiber without any Treatment under High Temperature}

N. Saeidi, M. N. Lotfollahi

School of Chemical, Gas and Petroleum Engineering, Semnan University, Semnan, Iran

PAPER INFO

جكيده

Paper history:

Received 05 March 2014

Received in revised form 18 May 2014

Accepted 22 May 2014

\section{Keywords:}

Activated Carbon Fiber

Organic Binder

Iodine Number

Adsorption Property

Mechanical Property

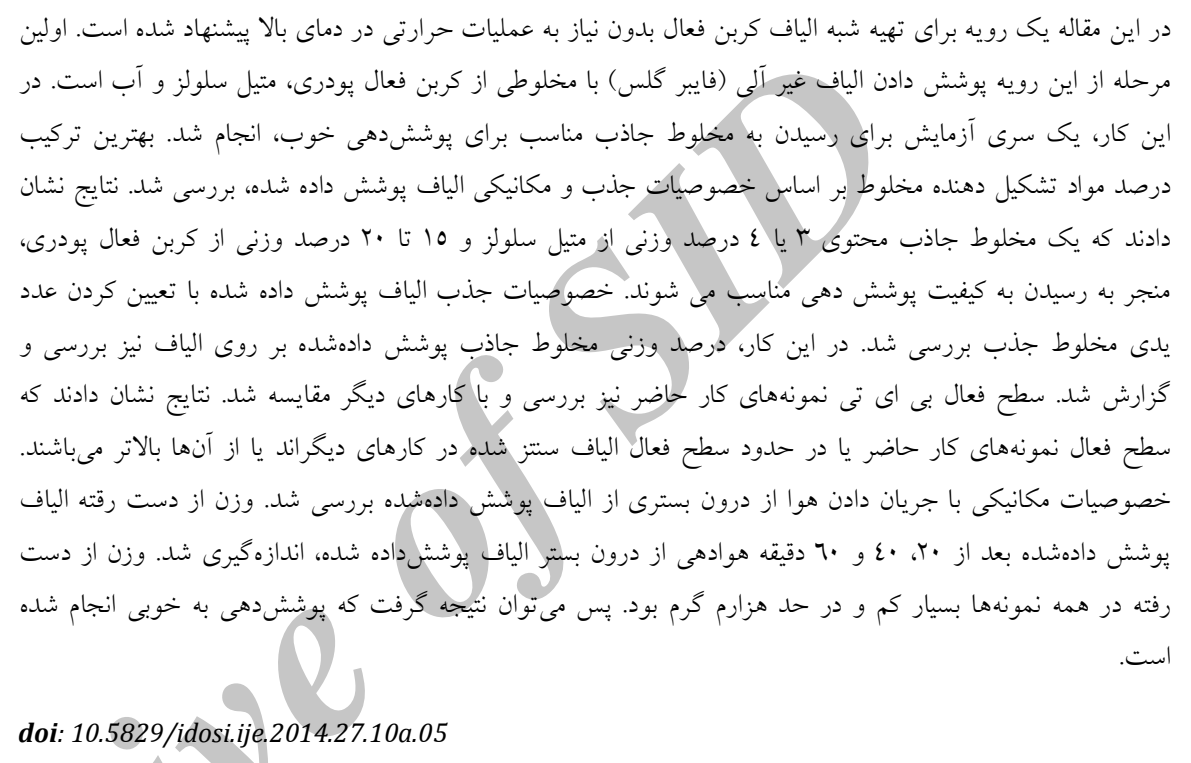

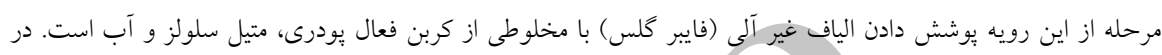

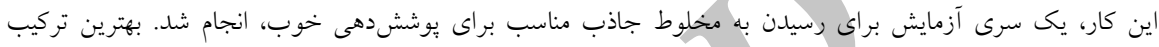

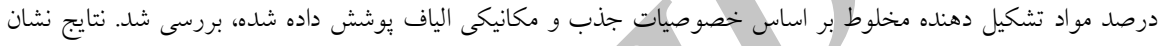

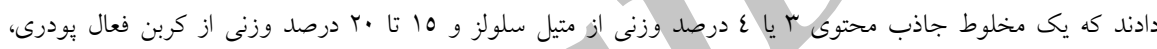

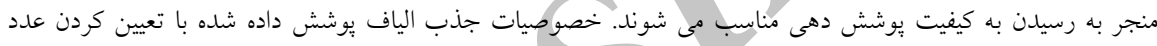

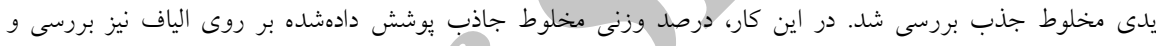

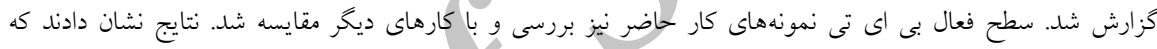

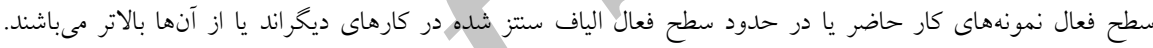

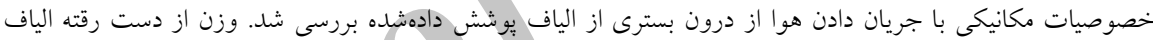

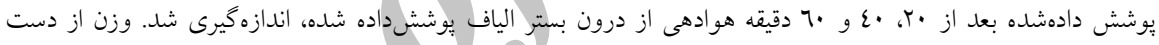




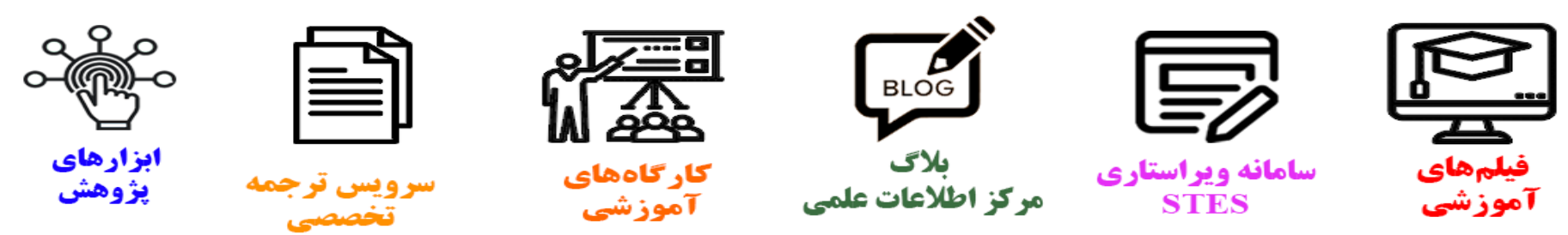

\section{(c)}

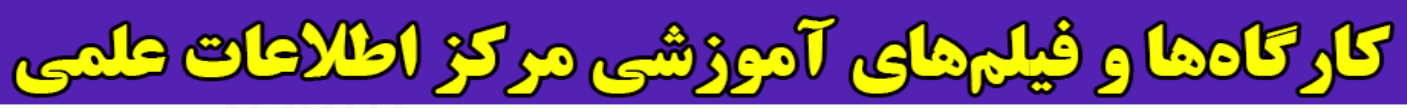
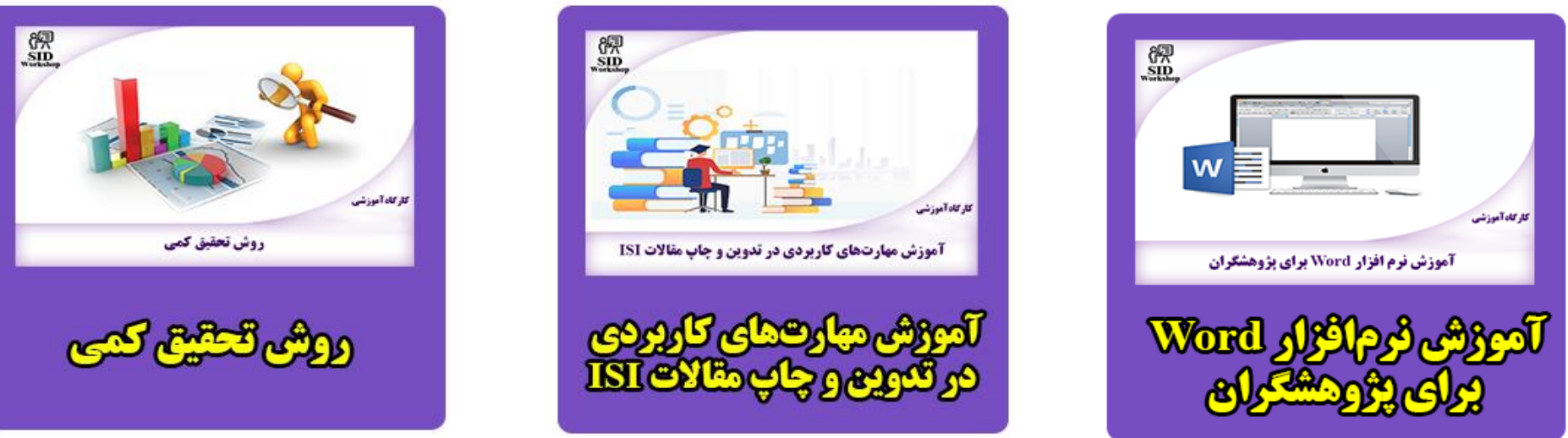